\title{
Remittances and chain migration: Longitudinal evidence from Bosnia and Herzegovina
}

\author{
Ralitza Dimova
}

François-Charles Wolff

August 2014

\begin{abstract}
Most of the literature on remittances focuses on their implications for the welfare of family members in the country of origin and disregards their role as facilitator of chain migration. We address this issue with the use of longitudinal data from Bosnia and Herzegovina, one of the primary exporters of migrants and recipients of remittances in the world. We find that remittances have a significant positive impact on the migration prospects of their recipients. Better endowed people are most likely to migrate, which highlights a potential negative implication of migration and remittances.
\end{abstract}

Classification JEL: J61, 015

Keywords: emigration intention, Bosnia and Herzegovina, remittances

* School of Environment and Development, University of Manchester.

Email: ralitza.dimova@manchester.ac.uk

** Corresponding author. LEMNA, Université de Nantes, France and INED, Paris, France.

E-mail: francois.wolff@univ-nantes.fr http://ideas.repec.org/e/pwo132.html 


\section{Introduction}

Over the past several decades, there has been increasing emphasis on the positive role played by international remittances in the process of economic development. Given that their sheer volume represents nearly three times the size of official development assistance and exceeds by far not only the overall flow of private debt and portfolio equity investments, but also the foreign exchange reserves of a large number of developing countries, remittances now occupy a paramount position among alternative sources of international finance for development (World Bank, 2013).

A number of studies have established that at least a portion of the remittances received are used for investment in human and physical capital (Hanson and Woodruff, 2002; Cox Edwards and Ureta, 2003; Hildebrand and McKenzie, 2005, Mesnard, 2004) and contribute to the reduction of poverty while having a negative or insignificant impact on inequality in the region or country of origin (Adams, 1992; Taylor and Wyatt, 1996). Furthermore, the literature that emphasizes the "brain gain" potential of the "brain drain" consequences of emigration (Beine et al., 2001; 2008) provides strong counter-arguments to evidence on negative implications of the outflow of human capital for both the home country of the migrants and family members left behind (Lucas, 1987; Rozelle et al, 1999; Cox Edwards and Ureta, 2003). It is therefore not surprising that influential development policy institutions like the World Bank argue in favour of reducing the cost of emigration from developing countries as part of the post-2015 development agenda (World Bank, 2013).

An important link that has remained largely unexplored is the possibility for migration and remittances to trigger chain migration. Although the literature on migration networks studies both theoretically and empirically the effect of emigration on the migration decisions of those left behind through either network externalities or herd behaviour (Epstein and Gang, 2006), it consists mostly of case studies that tend to sample on the dependent (network) variable and are thus potentially biased towards instances where such networks play their ascribed chain migration role (de Haas, 2010). At the same time, the literature on remittances focuses almost exclusively on their implications for the welfare of their recipients. However, if remittances are mostly channelled to sponsor prospective migrants and skills are primarily acquired to fuel further migration, the potentially positive implications of migration and remittances may be seriously undermined.

In this empirical paper, we focus on the possibility of a trigger effect of remittances on migration. Compared to Van Dalen et al. (2005a) who were the first to explore the correlation between remittances and the migration prospects of their recipients in three Middle East and African countries, we address the potential problems of both unobserved heterogeneity and reverse causality of remittances in the migration prospects estimation. Our geographic focus is Bosnia and Herzegovina $(\mathrm{BiH})$, which is the second largest non-OECD exporter of immigrants into the OECD. Its 
total stock of 2.2 million emigrants exceeds those of even India (1.9 million emigrants) and China (1.7 million emigrants). In addition, $\mathrm{BiH}$ is the second largest recipient of remittances in East Europe after Moldova (World Bank, 2008).

The rest of the study is organized as follows. In Section 2, we conceptualize the remittancesmigration nexus. The $\mathrm{BiH}$ context is discussed in Section 3. The data and pattern of migration intentions are described in Section 4. Section 5 outlines our empirical strategy and we discuss our empirical results in Section 6. Section 7 concludes.

\section{Conceptual framework}

To highlight briefly the theoretical intuition behind the link between remittances and the emigration decision of their recipients, let us consider a simple two-period setting ${ }^{i}$. In the first period, an individual resides and works in the country of origin. In the second period, she decides whether to stay in the country of origin or migrate to the destination country. We assume that consumption and other arguments in the utility function, such as preferences for living with family and friends in a familiar environment, are complements. In other words, the individual prefers to stay in the country of origin. Higher earnings in the destination country may tilt his decision in favour of emigration, but this would involve incurring migration costs.

In this simple framework, the decision to migrate is based on a comparison of the lifetime utility functions across the two different second period locations. It is straightforward to show that the optimal location decision depends on (i) the differences in earnings in the country of origin and the country of destination net of migration costs: specifically, migration would be a positive function of the wages in the destination country and a negative function of the migration costs, and (ii) the strength of the preference for remaining in the country of origin.

Let us now investigate the influence of remittances on the migration decision. The most popular (implicit) hypothesis about this relationship is that remittances would reduce the incentives of their recipients to emigrate. This argument is supported by substantial evidence that remittances improve the welfare of their recipients (Quartey and Blankson, 2004; Adams and Page, 2005). However, continuity of the flow of remittances is uncertain. Even altruistic donors may not be able to maintain their generosity if they experience difficulties in the destination country's labour market. Hence their decision to stay back in the country of origin is not guaranteed.

The rationale for emigration is therefore strong. To begin with, remittances provide a signal to their recipients that migration is a profitable undertaking. The signalling effect of remittances is backed by all stylized theories on the motivations to remit. As indicated by Rapoport and Docquier (2005, pp. 39), remittances are a positive function of the income of the migrant and are hence an 
indication of his or her financial success in the host labour market. Secondly, and in keeping with migration network theories, remittances could be perceived as a sign of strength of family ties and hence an indication that their recipient will be able to benefit from network externalities upon migration. Finally, remittances simply reduce the monetary cost of migration in the context of severe liquidity constraints in the country of origin ${ }^{\mathrm{ii}}$.

\section{The Bosnia and Herzegovina context}

We focus on Bosnia and Herzegovina, a Balkan Peninsula country bordering Croatia, Serbia and Montenegro and comprising of the following two autonomous entities: the Federation of $\mathrm{BiH}$ (FBH) which consists of 10 federal units and Republika Srpska. Formerly part of the Socialist Federative Republic of Yugoslavia, BiH declared its independence on March 1992 and received international recognition on April 6, 1992.

This date coincides with the beginning of the Bosnian war, which continued until December 1995. During that territorial conflict between Serbs on the one side and Bosniaks and Croats on the other side, around 100,000 people were killed and approximately 1.3 million people were displaced. GDP fell by around 75\%. Over 1.1 million of the displaced Bosnians resettled in FBH by the start of the 2000s (UNHCR, 2003). However, the Bosnian economy continued to face considerable difficulties. GDP per capita (expressed in constant 2000 US \$) was $2242 \$$ in $2000,2424 \$$ in 2002 and $2683 \$$ in 2004 , while the unemployment rate as percentage of total labour force in 2006 was estimated to be $31.8 \%$ iii.

These unfavourable economic conditions along with the Bosnian war nourished the migration decisions of many Bosnian inhabitants. Angrist and Kugler (2003) argue that the Balkan wars resulted in an important wave of "permanent" immigration from former Yugoslavia to OECD countries. In 2008, the main countries of destination for Bosnian migrants were United States $(390,000$ migrants), Germany $(157,200)$, Serbia $(137,000)$, Austria $(132,300)$ and Slovenia $(100,000)$ (Valenta and Ramet, 2011, p. 5). The contribution of personal remittances as percentage of GDP was estimated at $29.2 \%$ in $2000,22.9 \%$ in 2002 and $20.7 \%$ in 2004 . These numbers are impressive compared to those observed in neighbouring countries for the same period: $3 \%$ in Croatia, $0.6 \%$ in Hungary and $0.3 \%$ in Romania.

\section{Data and descriptive statistics}

We use the 2001-2004 panel data survey for $\mathrm{BiH}$, which is part of the Living Standards Measurement Study (LSMS) household surveys ${ }^{\text {iv }}$. The first wave was carried out in the fall of 2001 by three local statistical organizations (the State Agency for Statistics for BiH, the RS Institute of 
Statistics and the FBiH Institute of Statistics), with support from the Department for International Development of the British Government, the United Nations Development Program, the Japanese Government, and the World Bank. The original sample consisted of 5402 households, including 2,400 households in the Republika Srpska and 3,000 households in the Federation of $\mathrm{BiH}^{\mathrm{v}}$. The panel survey sample covering the 2001-2004 period is smaller. It consists of more than 3000 households drawn from the 2001 sample and re-interviewed in 2002, 2003 and 2004. The samples provided by the World Bank include 3,003 households in 2001, 3,086 in 2002, 3077 in 2003 and 2,837 in 2004.

The panel covers the standard for LSMS surveys wide range of welfare related topics, including the demographic composition of the household and detailed information on housing, education, health, labour, migration, credit, consumption, agricultural and non-agricultural activities. The key variables for our study are remittances and the probability to emigrate. On receipt of remittances, the $\mathrm{BiH}$ data set includes the following question: "In the last 12 months, have you received any money, gifts or services in kind from friends or family working abroad?". For households who gave a positive answer to this question, we also know the total amount of the transfer. Since the questionnaire does not include any information on private transfers (either locally or from abroad) in the first wave, we restrict our attention to the 2002-2004 period ${ }^{\mathrm{vi}}$.

The probability to migrate is proxied with two different indicators. The first indicator captures the desire of the respondent to migrate as an answer to the question: "If you could choose, would you stay here in your present place of residence or would you prefer to move somewhere else?". For respondents indicating that they would like to move, there is a second question: "Where would you like to move to: within the same municipality, another municipality, abroad, other?". We combine both sources of information to construct a dummy variable which is equal to one when the respondent has expressed a desire to emigrate to a foreign country. Our second indicator highlights the more definite probability to migrate as an answer to the question: "How likely do you think it is that you will move in the coming year: very likely, quite likely, not very likely, not likely at all ?". Our indicator of probability to emigrate is equal to one if either of the first three situations hold, and to zero when migrating to a foreign country is unlikely ${ }^{\text {vii }}$.

The use of data on migratory intentions as a proxy for the probability to migrate has now become popular in the literature (Dustmann, 2003, van Dalen et al., 2005a, 2005b, van Dalen and Henkens, 2008). The justification of this choice of proxy is based on the theory of reasoned action of social psychologists, which looks at a person's intention to undertake actions as a function of his or her beliefs about the consequences of his or her actions (Ajzen, 1985, Manski, 1990). Its plausibility has been confirmed by numerous studies on migration, which have found that the intention to 
migrate is a powerful predictor of the actual realization of the decision to emigrate permanently (see van Dalen et al., 2005b; Dustmann, 2003).

We construct a longitudinal data set where each individual in the household is counted as one observation. Only individuals between ages 15 and 45 are kept, as these individuals are more likely to migrate. After deleting $\mathbf{7 7 3}$ observations with missing information, we are left with a sample of 10,129 observations: 3,551 in waves 2, 3,446 in wave 3 and 3,132 in wave 4 . This corresponds to 3,604 individuals, $85.1 \%(\mathrm{~N}=3,068)$ of which were interviewed three times, $10.8 \%$ twice $(\mathrm{N}=389)$ and 4.1\% ( $\mathrm{N}=147)$ only once during the period. Our data indicate that as many as $30.2 \%$ of the respondents would like to migrate to a foreign country. Among those who have stated that they want to migrate to a foreign country, $69.2 \%$ indicate that emigration in the coming year is not likely. Hence, the proportion of respondents who believe that migration in the coming year is possible amounts to $9.3 \%$. The percentage is slightly higher for those living in a rural area (9.8\%). The average proportion of household members who have received remittances is equal to $8.3 \%$ over the period (8.9\% in $2002,7.2 \%$ in 2003 and $9 \%$ in 2004).

As our main interest is in the relationship between migration and remittances, we plot receipt of remittances against the desire to migrate (Figure 1) and the likelihood to migrate (Figure 2). Our results indicate that the intention to emigrate is positively correlated with the receipt of remittances. Respondents who have received transfers from abroad are much more likely to want to migrate to a foreign country than non-recipients, $37.6 \%$ against $29.6 \%$. The difference between recipients and non-recipients is much larger when we consider the possibility to migrate to a foreign country in the coming year: $18.8 \%$ against $8.4 \%$. Although preliminary, these descriptive statistics suggest that remittances may indeed have a positive influence on the probability to migrate.

$$
\begin{aligned}
& \text { Insert Figure } 1 \text { here } \\
& \text { Insert Figure } 2 \text { here }
\end{aligned}
$$

Table 1 highlights some characteristics of the individuals in the sample by desire to migrate to a foreign country, probability to migrate in the coming year and receipt of remittances. Unemployment is a strong push factor for migration and those who show interest in migrating to a foreign country are less likely to have a job (34.6\% against $44.9 \%)$. The pattern is similar if the propensity to migrate is proxied with the likelihood to migrate in the coming year ( $33.9 \%$ instead of 42.6\%). Healthier people face a higher probability of migrating, and the same is true for younger and single individuals. People in the lowest income categories are more likely to express a desire to migrate, but people in the intermediate income categories face a higher probability of migrating. The emigration probability is also strongly affected by the wealth index, which captures a more stable or long-term financial status of the household than the current income variable $e^{\text {viii }}$. 
Insert Table 1 here

As highlighted in the last two columns of Table 1, in general people who live fairly comfortably are less likely to receive remittances than people who have financial difficulties. The same is true for unemployed and sick people. These observations are consistent with the altruistic motive for transfers, whereby people in greater need are more likely to receive remittances than people who are relatively better off (Rapoport and Docquier, 2006). At the same time, the wealth index is higher among people receiving remittances than among people not receiving remittances, but this is probably on account of increased wealth accumulation through remittances. Finally, we observe that less educated people are slightly more likely to receive remittances than more educated people.

In sum, we see that while poverty and unemployment are strong push factors for migration, the likelihood to migrate appears to be positively correlated with the financial ability to cover the migration costs. We next explore the relationship between the receipt of remittances and the desire to migrate more rigorously.

\section{Econometric strategy}

We assume that there exists a latent variable $I_{i t}^{*}$ that represents the propensity of a person $i$ to emigrate at date $t$. By definition, this latent variable is unobserved, but we have information on the self-reported intention denoted by $I_{i t}$ such that $I_{i t}=1$ when $I_{i t}^{*} \geq 0$, and $I_{i t}=0$ otherwise. The latent variable $I_{i t}^{*}$ can be modeled in the following linear way:

$$
I_{i t}^{*}=Z_{i t} \beta+\delta R_{i t}+\varepsilon_{i t}
$$

where $Z_{i t}$ is a set of individual characteristics (except remittances) which influence the emigration intention, $\beta$ is the associated vector of parameters, $R_{i t}$ captures the receipt of remittances, $\delta$ measures the effect of remittances on the emigration intention, and $\varepsilon_{i t}$ is a normally distributed residual. Under the assumption that $R_{i t}$ is exogenous, a Probit model would give us an unbiased estimate of the remittance effect $\delta$.

Whether the exogeneity assumption is plausible in our context is an important issue that one needs to take into account. There are two important potential causes of endogeneity bias ${ }^{\text {ix }}$. One is unobserved heterogeneity: the possibility that the same unobserved factors affect both the receipt of remittances and the intention to emigrate. Let us consider for instance the case of a poor country, subject to frequent economic crises and conflicts, whose inhabitants are trying to leave. There is a high probability that the low living standards of family members left behind increase their desire to migrate and at the same time increase their probability of receiving remittances. 
Secondly, there is the issue of simultaneity. Given that we use the intention to migrate as a dependent variable, this would be less of a problem than if we used instead a contemporaneous measure of migration. But even if we consider the impact of remittances on the desire or likelihood to migrate, we cannot completely rule out the possibility of reverse causality. Consider for instance a household, consisting of two members: a person who has already migrated and his/her spouse or child who is still in the country of origin. There is a high probability that the person who is still in the country of origin wants to migrate and join the migrant and therefore the observed receipt of remittances could be conditional on that desire to reunite.

Since we have longitudinal data, we are able to account for unobserved heterogeneity at the individual level by estimating random and fixed effect models. Let $\varepsilon_{i t}=u_{i}+\xi_{i t}$, where $u_{i}$ is an individual specific component and $\xi_{i t}$ is a residual. The term $u_{i}$ picks up all the unobserved timeinvariant characteristics specific to the individual. Under the assumption that the covariates introduced in (1) are not correlated with the individual effect $u_{i}$, the appropriate specification is a random effect Probit model. By contrast, if $E\left(u_{i} \mid Z_{i t}, R_{i t}\right) \neq 0$, we rely on a fixed effect model. Since the dependent variable is binary, the model is estimated with the use of a conditional maximum likelihood method (Chamberlain, 1980).

Since remittances are likely to be allocated to a non-random (with respect to their intention to migrate) sample of people, we also need to take the possibility of selection bias into account. While an instrumental variable approach would be the ideal way of addressing this problem, it is virtually impossible to find suitable instruments, especially given that we do not have information on the characteristics of the people that have already migrated ${ }^{x}$. We therefore opt for the alternative of using a method that involves selection on observables. The receipt of remittances can be viewed as a treatment variable, whereby recipients are allocated to the treated group and non-recipients are allocated to the control group. We seek to estimate the average treatment effect on the treated (ATT) conditional on covariates $X$, where for the sake of simplicity we omit the year of observation $t$ from our notation:

$$
A T T=E\left(Y_{1} \mid R=1, X\right)-E\left(Y_{0} \mid R=1, X\right)
$$

where $Y=Y_{1}$ if $R=1$ and $Y=Y_{0}$ if $R=0$. The main challenge with the estimation of (2) is that the expected conditional outcome $E\left(Y_{0} \mid R=1, X\right)$ is not observed.

When researchers have access to longitudinal data with information on both treated and control observations before the treatment, the appropriate strategy is a difference-in-differences estimator with matching (Heckman et al., 1998, 1999). Consider the following two-period setting, where $t_{1}$ and $t_{2}$ are the pre- and post-intervention periods respectively. Then, the ATT after the intervention is: 


$$
A T T=E\left(Y_{1 t_{2}} \mid R=1, X\right)-E\left(Y_{0 t_{2}} \mid R=1, X\right)
$$

The difference-in-differences estimator assumes that differences in outcomes between treated and control units is time-invariant, conditional on $X$. Formally, this corresponds to the condition $E\left(Y_{0 t_{1}} \mid R=1, X\right)-E\left(Y_{0 t_{1}} \mid R=0, X\right)=E\left(Y_{0 t_{2}} \mid R=1, X\right)-E\left(Y_{0 t_{2}} \mid R=0, X\right) . \quad$ Under $\quad$ this assumption, it is straightforward to show that the ATT is identified conditional on $X$ :

$$
A T T=\left[E\left(Y_{1 t_{2}} \mid R=1, X\right)-E\left(Y_{0 t_{2}} \mid R=0, X\right)\right]-\left[E\left(Y_{0 t_{1}} \mid R=1, X\right)-E\left(Y_{0 t_{1}} \mid R=0, X\right)\right]
$$

The matching estimator corresponds to the difference-in-differences of outcomes between the treated and control units before and after the treatment, respectively. Unfortunately, we cannot apply such estimator since at each wave of the survey respondents have the possibility of receiving remittances (our treatment variable). Under additional assumptions, Nguyen (2012) has recently shown that when data is not available from before the start of the treatment, it is still possible to recover the ATT conditional on $X$ with some adjustments on the matching procedure.

Let $R_{t_{1}}$ and $R_{t_{2}}$ be two dummy variables indicating the receipt of remittances at year $t_{1}$ and $t_{2}$ respectively. Then, the $A T T$ for the second period is:

$$
A T T=E\left(Y_{1 t_{2}} \mid R_{t_{2}}=1, X\right)-E\left(Y_{0 t_{2}} \mid R_{t_{2}}=1, X\right)
$$

where $E\left(Y_{0 t_{2}} \mid R_{t_{2}}=1, X\right)$ is unobserved by definition. From (5), it follows that:

$$
\begin{aligned}
& A T T=\operatorname{Pr}\left(R_{t_{1}}=1 \mid R_{t_{2}}=1, X\right) *\left[E\left(Y_{1 t_{2}} \mid R_{t_{1}}=1, R_{t_{2}}=1, X\right)-E\left(Y_{0 t_{2}} \mid R_{t_{1}}=1, R_{t_{2}}=1, X\right)\right] \\
& +\operatorname{Pr}\left(R_{t_{1}}=0 \mid R_{t_{2}}=1, X\right) *\left[E\left(Y_{1 t_{2}} \mid R_{t_{1}}=0, R_{t_{2}}=1, X\right)-E\left(Y_{0 t_{2}} \mid R_{t_{1}}=0, R_{t_{2}}=1, X\right)\right]
\end{aligned}
$$

The two following assumptions are necessary for identification:

$$
\begin{gathered}
E\left(Y_{0 t_{2}} \mid R_{t_{1}}=0, R_{t_{2}}=1, X\right)-E\left(Y_{0 t_{2}} \mid R_{t_{1}}=0, R_{t_{2}}=0, X\right)= \\
E\left(Y_{0 t_{1}} \mid R_{t_{1}}=0, R_{t_{2}}=1, X\right)-E\left(Y_{0 t_{1}} \mid R_{t_{1}}=0, R_{t_{2}}=0, X\right) \\
E\left(Y_{0 t_{2}} \mid R_{t_{1}}=1, R_{t_{2}}=1, X\right)-E\left(Y_{1 t_{1}} \mid R_{t_{1}}=1, R_{t_{2}}=1, X\right)= \\
E\left(Y_{0 t_{2}} \mid R_{t_{1}}=1, R_{t_{2}}=0, X\right)-E\left(Y_{1 t_{1}} \mid R_{t_{1}}=1, R_{t_{2}}=0, X\right)
\end{gathered}
$$

The interpretation of (7) and (8) is as follows. The first assumption indicates that the difference in the non-intervention outcome between respondents who never receive a transfer and those who receive a transfer in period 2 only remains unchanged over time ${ }^{x i}$. The second assumption states that the difference between the non-intervention outcome in period 2 and the intervention outcome in period 1 is the same for people receiving remittances in periods 1 and 2 and for people receiving remittances only in period 1 . Combining (6), (7) and (8) gives:

$$
\begin{aligned}
A T T= & \operatorname{Pr}\left(R_{t_{1}}=1 \mid R_{t_{2}}=1, X\right) *\left\{\left[E\left(Y_{1 t_{2}} \mid R_{t_{1}}=1, R_{t_{2}}=1, X\right)-E\left(Y_{0 t_{2}} \mid R_{t_{1}}=1, R_{t_{2}}=0, X\right)\right]\right. \\
& \left.-\left[E\left(Y_{1 t_{1}} \mid R_{t_{1}}=1, R_{t_{2}}=1, X\right)-E\left(Y_{1 t_{1}} \mid R_{t_{1}}=1, R_{t_{2}}=0, X\right)\right]\right\} \\
& +\operatorname{Pr}\left(R_{t_{1}}=0 \mid R_{t_{2}}=1, X\right) *\left\{\left[E\left(Y_{1 t_{2}} \mid R_{t_{1}}=0, R_{t_{2}}=1, X\right)-E\left(Y_{0 t_{2}} \mid R_{t_{1}}=0, R_{t_{2}}=0, X\right)\right]\right. \\
& \left.-\left[E\left(Y_{0 t_{1}} \mid R_{t_{1}}=0, R_{t_{2}}=1, X\right)-E\left(Y_{0 t_{1}} \mid R_{t_{1}}=0, R_{t_{2}}=0, X\right)\right]\right\}
\end{aligned}
$$


There are now two matching procedures, conditional on $X$. The first consists of matching people who have received transfers in both periods with people who have received transfers only in the first period, while the second consists of matching people who have received transfers in the second period only with people who never received transfers. Matching is based on the propensity score (Rosenbaum and Rubin, 1983). We estimate separate regressions to predict the probability for an individual to receive a transfer in period 2 , conditional on the receipt of remittances in period 1.

\section{Results}

\section{Estimates with exogenous remittances}

As a preliminary step, we treat remittances as an exogenous variable. We study the impact of remittances on the propensity of their recipients to migrate using both random effect Probit and conditional fixed effect Logit models. The corresponding estimates are presented in Table 2, for both the desire of an individual to migrate and the more definite likelihood of an individual to migrate during the coming year.

Insert Table 2 here

According to the random effect estimates (columns $1 \mathrm{~A}$ and $2 \mathrm{~A}$ ), educated people are both more interested in migration and more likely to migrate ${ }^{x i i}$. While people in worse current financial situations express greater desire to migrate, the current financial situation does not have a significant impact on the likelihood to migrate in the coming year ${ }^{\text {xiii }}$. By contrast, this likelihood is positively influenced by the wealth status of the household. Unemployment has a strong positive impact on not only the desire, but also the likelihood to migrate, and people in rural areas are more likely to migrate than people in urban areas. We also find that single and younger people are much more likely to migrate than middle-aged and married people, and the same is true for healthy people. Finally, larger household sizes have a negative impact on the likelihood to migrate to a foreign country ${ }^{\text {xiv }}$.

Let us now focus on the remittance dummy variable. As shown in columns $(1 A)$ and $(2 A)$, the receipt of remittances has a positive and significant influence on the desire to migrate to a foreign country at the 1 percent level. To assess the magnitude of the transfer variable, we use a linear probability model. We find that the receipt of remittances is associated with a 5.9 percentage points higher probability of the intention to migrate $(\mathrm{t}=3.67)$ and 9.1 percentage points higher definite likelihood to migrate to a foreign country in the coming year ( $t=8.67)$. Keeping in mind that $30.2 \%$ of respondents intend to migrate and $9.3 \%$ intend to do that in the coming year, this means that our estimates correspond to a $19.5 \%$ difference and $97.8 \%$ difference between the corresponding migration outcomes for recipients and non-recipients of transfers, respectively. 
However, the random effect framework is based on the restrictive assumption that the individual specific errors are uncorrelated with the explanatory variables. Hence, we next use a fixed effect model. When estimating the conditional Logit model, the regression is estimated on the subsamples of individuals who have indicated at least once over the selected period that they intend to migrate ${ }^{\mathrm{xv}}$. This substantially reduces the sample size: the models explaining the desire to move abroad and possible migration in the coming year consist of 1,490 and 678 individuals, respectively (amounting to 4,361 observations and 2,420 observations overall).

To make the random effect and the fixed effect results comparable and differences of results not driven simply by differences in samples, we re-estimate the random effect Probit model on these restricted subsamples. As shown in columns (1B) and (2B), the story does not change significantly, but a few covariates lose their significance compared to those based on the whole sample. In particular, the correlation between remittances and preferences for moving abroad is no longer significant (albeit still positive), while those receiving money from abroad are more likely to migrate in the coming year.

The conditional fixed effect estimates are highlighted in columns (1C) and (2C). Characteristics that are constant over time (like gender and education) drop from the regression, as they are picked up by the individual fixed effect. Our results are very similar to those based on the random effect regressions. On the one hand, the coefficient of the remittance variable in the desire to migrate regression loses its significance. However, recall that this indicator of migration plans may be capturing only a vague desire of living somewhere else, without any assurance that this would eventually translate into actual migration. On the other hand, the coefficient of the remittances variable in the likelihood to migrate regression continues to be positive and significant (at the 1 percent level) $)^{x v i}$. In sum, our results support the hypothesis of a positive impact of remittances on the probability to migrate, especially when this probability is proxied with a more definite measure of migration potential like the likelihood to migrate in the forthcoming twelve months.

\section{Accounting for endogeneity of remittances}

We now relax the assumption of exogeneity of remittances and extend our analysis to a selection on observables framework. As a preliminary step, we estimate a random effect Probit regression, explaining the probability that a respondent receives remittances in a given year. The list of covariates which we use to explain the receipt of money from abroad includes gender, age, marital status, number of people in the household, educational attainment, a dummy variable for excellent self-reported health, occupational status, indicating whether the person has a job or is unemployed (the omitted category being out of the labour force), and urban, mixed or rural residence. We 
exclude the set of indicators related to the financial situation and wealth of the household as these covariates may themselves be a result of the receipt of remittances.

The results reported in column (3) of Table 2 show that unemployed people face a higher probability of receiving transfers while the opposite is true for people who have a job. Both results are consistent with the altruistic motive for transferring resources, according to which less well-off people should have a higher propensity of being helped. Compared to married people, single individuals face a lower probability of receiving remittances. The proportion of female recipients is lower compared to that of male recipients. Neither education nor age have significant impact on the receipt of transfers. Overall, the results suggest that remittances are driven by a more complex set of motives than sheer altruism ${ }^{\mathrm{xvi}}$.

\section{Insert Table 3}

We use several methods to account for selection on the basis of observables, which consists of a comparison of outcomes using treated and control subjects as similar as possible for a given set of covariates. To control for the confounding influence of pre-treatment control variables, we use the following three estimators: matching, based on the propensity score (Becker and Ichino, 2002), the coarsened exact matching estimator which is robust to measurement errors and restricts the matched data to areas of common empirical support (Blackwell et al., 2009, lacus et al., 2011), and the entropy balancing estimator which relies on a maximum entropy reweighting scheme (Hainmueller, 2012) ${ }^{\text {xiii }}$. We proceed in two steps. First, we assume that the year-specific observations for each respondent are independent and calculate the difference in outcomes for the treated and control groups after matching. Second, we calculate the more complex estimator given by (9).

The results from the three different matching estimators are presented in Table 3. For each outcome, we apply these estimators both to the whole sample (panels A1 and B1) and to the subsamples comprising individual with time-varying preferences for migration (panels A2 and B2). Under the assumption of exogeneity of remittances, the difference in desire to migrate to a foreign country between the treated and the control groups is equal to 0.081 , which is positive and significant (37.6\% for recipients and $29.6 \%$ for non-recipients, respectively). After matching and independent of the selected estimator, we find a value ranging between 7.5 and 8 percentage points for the difference in preferences for moving abroad between recipients and non-recipients (panel A1). The difference is much lower (around 3 percentage points) and not significant when selecting individuals with time-varying preferences for emigration (panel A2).

The results based on the second indicator of possible emigration to a foreign country in the coming year are very similar, but greater in magnitude. For the whole sample (panel B1), the unmatched difference is equal to 0.104 and is significant at the 1 percent level. After matching, the 
difference between recipients and non-recipients remains about 11 percentage points whatever the matching technique. This value is slightly lower at around 8-9 percentage points for individuals whose preferences for a migration in the coming year have changed over the period, but the gap remains statistically significant at the 5 percent level.

Finally, we use the matching estimator with longitudinal data to measure the impact of the receipt of remittances. In the case of preferences for moving abroad, we find that the ATT for this indicator is 3.9 percentage points for the 2002-2003 period and 3.3 percentage points for the 20032004 period. This is nearly twice lower than the other matching estimators that were based on the assumption that the repeated observations for each respondent were independent. In the case of the more definite possibility of migration to a foreign country in the coming year, we find much higher values for the ATT: 10.8 percentages points in 2003 and 6.5 percentage points in 2004 . Further, the standard errors obtained by a bootstrap procedure (0.041 and 0.029 , respectively) indicate that these ATTS are statistically significant ${ }^{\mathrm{xix}}$. Overall, our results show a positive impact of remittances on the probability to emigrate after controlling for the possibility of non-random selection of individuals into the transfer treatment.

\section{Concluding comments}

The impact of migration and remittances on the welfare of family members and communities remaining in the country of origin has long attracted the attention of both academics and policy makers. Findings on the positive implications of remittances, such as increase in investment in human and physical capital and poverty reduction seem to have overshadowed worries about the negative implications of migration and brain drain on the local economy and the welfare of households left behind. At the same time, little attempt has been made to explore the important issue of whether migration and remittances sent back to the country of origin stimulate chain migration. If this is indeed the case, and if remittances are mainly channelled to sponsor prospective migrants, much of the rationale behind arguments in favour of the positive implications of migration may be seriously undermined.

We attempt to close the gap in the literature by testing the hypothesis of a positive impact of remittances sent by family members abroad on the migration prospects of those still in the country of origin. We use as a case study $\mathrm{BiH}$, one of the primary exporters of migrants and recipients of remittances in the world. We find that remittances have a positive impact on the migration prospects of potential migrants. Expectations of a possible migration to a foreign country in the coming year are higher by a range of 6-10 percentage points for respondents receiving remittances, compared to respondents that do not receive remittances. We also find that young, healthy and well-educated 
people are most likely to migrate, which of course has significant potential implications on issues such as labour shortage and economic development prospects of the community and country of origin.

By looking at emigration intention of respondents aged between 15 and 45, our empirical analysis deals with the case of chain migration, most likely linked to labour market considerations. As indicated in our conceptual framework, one of the most plausible channels of a positive impact of remittances on chain migration is the situation where remittances are viewed by potential emigrants as a signal of better economic prospects in the host country. For older migrants, another form of chain migration related to strong family links may occur when migrants in the host country attempt to facilitate the arrival of their ageing parents (by sending them money) either to be able to look after them or to receive their support in raising kids. As a consequence, we decided to re-estimate all our regressions for the sample of individuals in the 46-60 age group ${ }^{\mathrm{xx}}$.

As expected, we find that the intention to emigrate is much less frequent among older individuals: around $12.5 \%$ of those aged between 46 and 60 claim that they would like to go abroad and only $2.8 \%$ report a possible migration in the coming year. However, the correlation between the emigration intention and remittances is also positive for the 46-60 age group. With the random effect specification, this correlation is significant for both the preference for moving abroad outcome $(t=2.17)$ and for the possible migration to a foreign country in the coming year outcome $(t=3.40)$. Furthermore, when we compare the 18-45 and 46-60 age groups, we do not find any difference in the role played by the remittance variable ${ }^{\mathrm{xxi}}$.

In sum, our results cast shadow on academic and policy related enthusiasm with the development enhancing potential of emigration from and remittances towards less developed countries. One could argue that our results are based on the special case of a country, which has undergone a major political crisis and despite post-crisis recovery, the local conditions for realizing the positive development enhancing (human capital accumulation, business growth, ...) effect of remittances do not exist. However, this context is typical of the majority of developing countries that rely excessively on remittances as a form of finance for development and are prone to frequent political and economic crises. With a dose of caution, we can argue that as with other forms of finance for development, the beneficial potential of remittances can hardly be realized if the threshold conditions for sustainable growth and poverty alleviation are not reached. 


\section{References}

Adams, R. (1992) The impact of migration and remittances on inequality in rural Pakistan. Pakistan Development Review, 31(4), pp. 1189-1203.

Adams, R. and Page, J. (2005). Do international migration and remittances reduce poverty in developing countries? World Development, 33 (10), pp. 1647-1669.

Ajzen, I. (1985) From intentions to actions: a theory of planned behavior, in: J. Kuhland J. Beckmann (eds) Action Control, Springer, Berlin, pp. 11-40.

Angrist, J. and Kugler, A. (2003). Protective or counter-productive? Labour market institutions and the effect of immigration on EU natives. The Economic Journal, 113, pp. 302-331.

Azam, J.P. and Gubert, F. (2005) Those in Kayes. The impact of remittances on their recipients in Africa. Revue Economique, 56(6), pp. 1331-1358.

Becker, S. and Ichino, A. (2002). Estimation of average treatment effects based on propensity scores. The Stata Journal, 2(4), pp. 358-377.

Beine, M., Docquier, F. and Rapoport, H. (2001) Brain drain and economic growth: Theory and evidence. Journal of Development Economics, 64(1), pp. 275-289.

Beine, M., Docquier, F. and Rapoport, H. (2008) Brain drain and human capital formation in developing countries: Winners and losers. Economic Journal, 118(528), pp. 631-652.

Blackwell, M., lacus, S., King, G. and Porro, G. (2009) Coarsened exact matching in Stata. Stata Journal, 9(4), pp. 524-546.

Chamberlain, G. (1980) Analysis of covariance with qualitative data. Review of Economic Studies, 47(1), pp. 225-238.

Cox Edwards, A. and Ureta, M. (2003) International migration, remittances and schooling: Evidence from El Salvador. Journal of Development Economics, 72(2), pp. 429-461.

van Dalen, H., Groenewold, G. and Fokkema, T. (2005a) The effect of remittances on emigration intentions in Egypt, Morocco and Turkey. Population Studies, 59(3), pp. 375-392.

van Dalen, H., Groenewold, G. and Fokkema, T. (2005b) "Out of Africa: what drives the pressure to emigrate? Journal of Population Economics, 18(4), pp. 741-778.

van Dalen, H. and Henkens, K. (2008) Emigration intentions: mere words or true plans? Explaining international migration and behavior. Mimeo, Tilburg University, Netherlands.

Dustmann, C. (1997). Return migration, uncertainty and precautionary savings. Journal of Development Economics, 52, pp. 295-316.

Dustmann, C. (2003) Children and return migration. Journal of Population Economics, 16(4), pp. 815830.

Epstein, G. and Gang, I. (2006). The influence of others on migration plans. Review of Development Economics, 10(4), pp. 652-665.

Filmer, D. and Pritchett, L. (2001) Estimating wealth effects without expenditure data or tears: An application to educational enrollments in states of India. Demography, 38(1), pp. 115-132.

Gardner, R.W., DeJong, G.F., Arnold, F. and Carino, B.V. (1986) The best-laid schemes: An analysis of discrepancies between migration intentions and behavior. Population and Environment, 8(12), pp. 63-77.

de Haas, H. (2010). Migration and development. A theoretical perspective. International Migration Review. 44(1), 227-264. 
Hainmueller, J. (2012) Entropy balancing: A multivariate reweighting method to produce balanced samples in observational studies. Political Analysis, 20(1), pp. 25-46.

Hanson, G.H. (2010) International migration and the developing world, in: D. Rodrik and M. Rosenzweig (eds) Handbook of Development Economics, North Holland, Elsevier, 5, pp. 43634414.

Hanson, G.H. and Woodruff, C. (2002) Emigration and educational attainment in Mexico. Mimeo, University of California at San Diego.

Heckman, J., Ichimura, H., Smith, J. and Todd, P. (1998) Characterizing selection bias using experimental data. Econometrica, 66(5), pp. 1017-1098.

Heckman, J., Lalonde, R. and Smith, J. (1999) The economics and econometrics of active labor market programs, in A. Ashenfelter and D. Card (eds) Handbook of Labor Economics, North Holland, Elsevier, 3, pp. 1865-2097.

Hildebrand, N. and McKenzie, D. (2005) The effects of migration on child health in Mexico. Economia, 6(1), pp. 257-289.

lacus, S., King, G. and Porro, G. (2011) Multivariate matching methods that are monotonic imbalance bounding. Journal of the American Statistical Association, 106(493), pp. 345-361.

Lucas, R.E.B. (1987) Emigration to South Africa's mines. American Economic Review, 77(3), pp. 313330.

Manski, CF. (1990) The use of intentions data to predict behavior: a best-case analysis. Journal of the American Statistical Association, 85(412), pp. 934-940.

Mesnard, A. (2004) . Oxford Economic Papers, 56(2), pp. 242-262.

Nguyen, C. (2012) Program impact evaluation using a matching method with panel data. Statistics in Medicine, 31(6), pp. 577-588.

Quartney, P. and Blankson, T. (2004). Do migrant remittances reduce the impact of macro-volatility in Ghana? Mimeo, Final report to the Global Development Network, International Monetary Fund.

Rapoport, H. and Docquier, F. (2006) The economics of migrants' remittances, in S.-C. Kolm and J. Mercier Ythier (eds) Handbook of the Economics of Giving, Altruism and Reciprocity, North Holland, Elsevier, 2, pp. 1135-1198.

Rosenbaum, P and Rubin,R. (19 83). The central role of propensity score in observational studies for causal effects. Biometrika, 70(1), 41-55.

Rozelle, S., Taylor, J.E. and de Braun, A. (1999) Migration, remittances and agricultural productivity in China. American Economic Review, 89(2), pp. 287-291.

Stark, O. (1995) Altruism and Beyond, Cambridge University Press.

Stark, O. and Wang, Y.Q. (2002) Migration dynamics. Economic Letters, 76(2), pp. 159-164.

Taylor, J.E. and Wyatt, T.J. (1996) The shadow value of migrant remittances, income and inequality in the household-farm economy. Journal of Development Studies, 32(6), pp. 899-912.

Valenta, M. and Ramet, S.P. (2011) The Bosnian Diaspora: Integration in Transnational Communities, Ashgate Publishing.

World Bank (2008) The Migration and Remittances Factbook 2008. 
World Bank (2013) Migration and remittance flows: Recent trends and outlook 2013-2016, Migration and Remittance Brief 21, Migration and Remittance Team, Development Prospects Group of the World Bank. 
Figure 1. Preferences for moving abroad and receipt of remittances

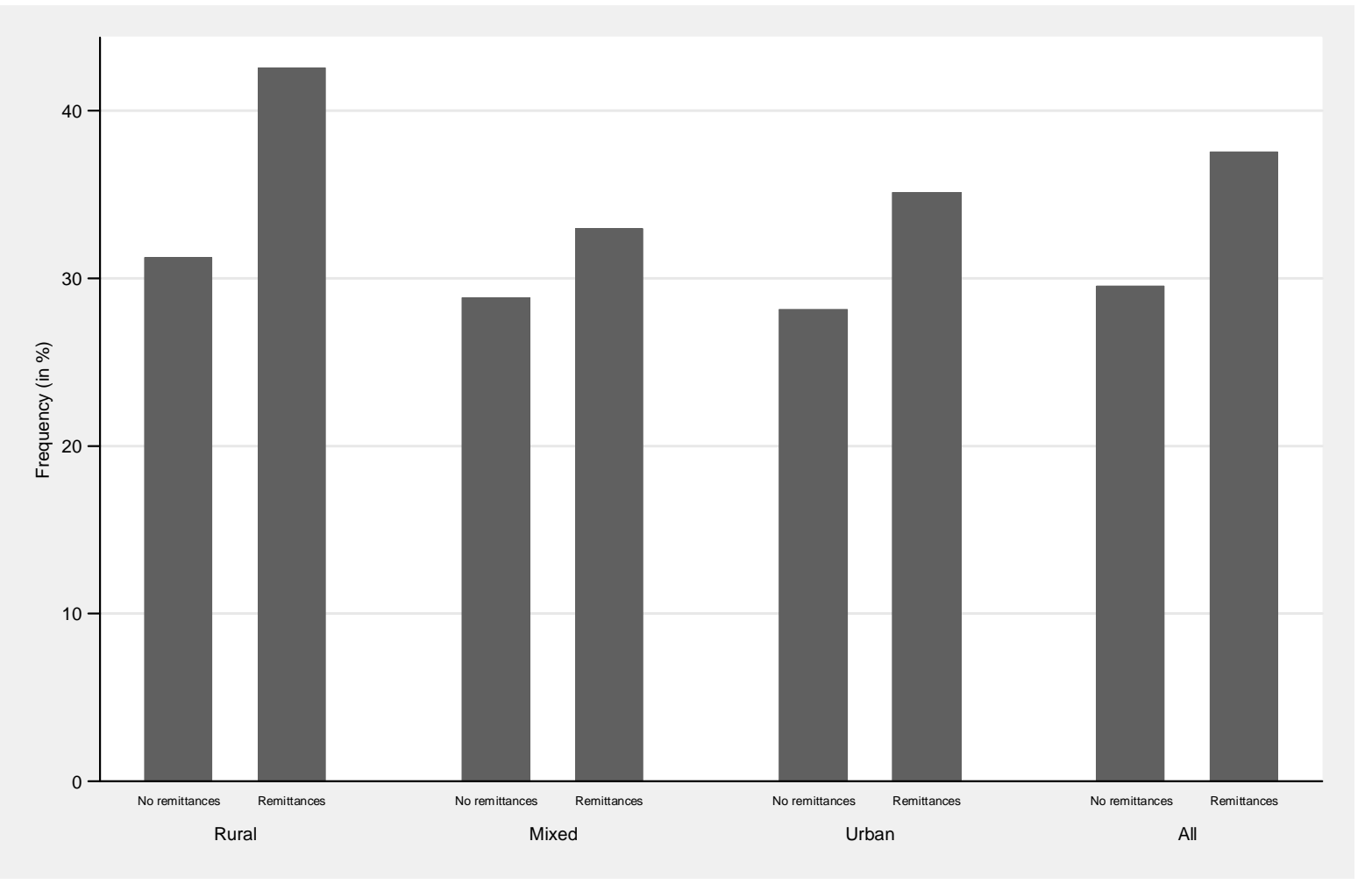

Source: authors' calculations, LSMS BIH 2002-2004. 
Figure 2. Possible migration to a foreign country in the coming year and receipt of remittances

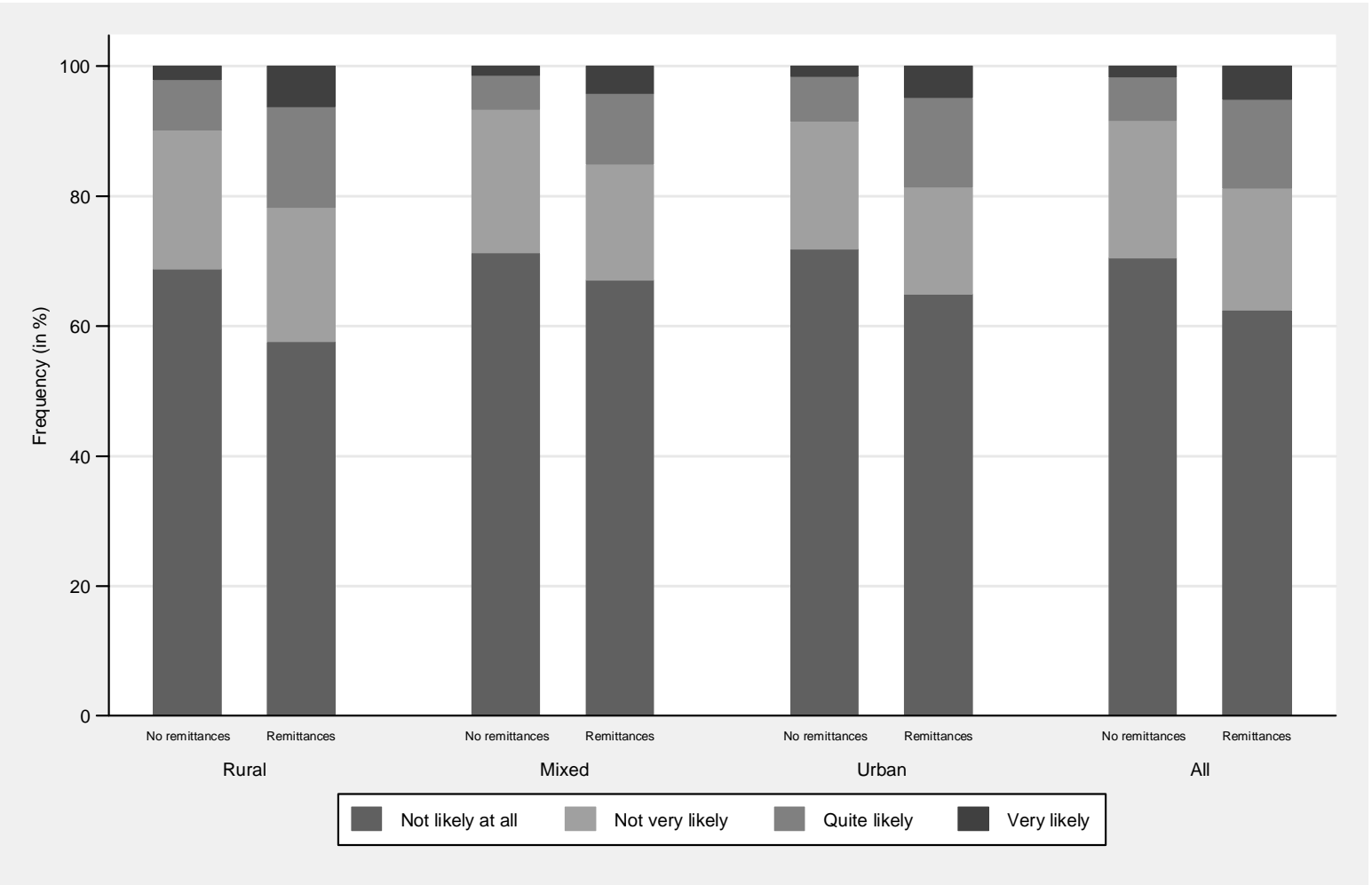

Source: authors' calculations, LSMS BIH 2002-2004. 
Table 1. Descriptive statistics of the sample

\begin{tabular}{|c|c|c|c|c|c|c|c|c|}
\hline \multirow{2}{*}{\multicolumn{2}{|c|}{ Variables }} & \multicolumn{2}{|c|}{$\begin{array}{l}\text { Preferences for } \\
\text { moving abroad }\end{array}$} & \multicolumn{2}{|c|}{$\begin{array}{l}\text { Possible migration } \\
\text { in the coming year }\end{array}$} & \multicolumn{2}{|c|}{ Remittances } & \multirow[t]{2}{*}{ All } \\
\hline & & No & Yes & No & Yes & No & Yes & \\
\hline \multicolumn{2}{|l|}{ Female } & 0.509 & 0.467 & 0.503 & 0.430 & 0.488 & 0.583 & 0.496 \\
\hline \multicolumn{2}{|l|}{ Age } & 31.833 & 29.012 & 31.323 & 27.634 & 30.942 & 31.402 & 30.980 \\
\hline \multirow[t]{3}{*}{ Marital status } & Married & 0.574 & 0.466 & 0.559 & 0.361 & 0.537 & 0.584 & 0.541 \\
\hline & Divorced/widowed & 0.045 & 0.035 & 0.044 & 0.024 & 0.039 & 0.075 & 0.042 \\
\hline & Single & 0.381 & 0.500 & 0.396 & 0.614 & 0.424 & 0.341 & 0.417 \\
\hline \multicolumn{2}{|c|}{ Number of persons in the household } & 4.011 & 3.978 & 4.019 & 3.826 & 4.023 & 3.755 & 4.001 \\
\hline \multirow[t]{4}{*}{ Education } & No diploma & 0.060 & 0.042 & 0.058 & 0.022 & 0.054 & 0.058 & 0.055 \\
\hline & Primary school & 0.309 & 0.349 & 0.320 & 0.330 & 0.318 & 0.352 & 0.321 \\
\hline & Secondary school & 0.578 & 0.578 & 0.575 & 0.608 & 0.580 & 0.553 & 0.578 \\
\hline & Junior college - University & 0.052 & 0.032 & 0.047 & 0.039 & 0.047 & 0.037 & 0.046 \\
\hline \multicolumn{2}{|c|}{ Excellent self-reported health } & 0.299 & 0.328 & 0.294 & 0.442 & 0.312 & 0.267 & 0.308 \\
\hline \multicolumn{2}{|c|}{ Has a job } & 0.449 & 0.346 & 0.426 & 0.339 & 0.426 & 0.333 & 0.418 \\
\hline \multicolumn{2}{|l|}{ Unemployed } & 0.230 & 0.365 & 0.260 & 0.379 & 0.264 & 0.344 & 0.271 \\
\hline & 0.110 & 0.184 & 0.134 & 0.117 & 0.135 & 0.111 & 0.133 \\
\hline & situation Quite difficult & 0.170 & 0.273 & 0.198 & 0.237 & 0.198 & 0.236 & 0.201 \\
\hline & Just about getting by & 0.390 & 0.376 & 0.384 & 0.402 & 0.384 & 0.404 & 0.386 \\
\hline & Doing alright & 0.282 & 0.147 & 0.245 & 0.209 & 0.243 & 0.226 & 0.241 \\
\hline & Living comfortably & 0.048 & 0.019 & 0.040 & 0.035 & 0.041 & 0.023 & 0.039 \\
\hline \multicolumn{2}{|l|}{ Wealth index } & 0.304 & 0.051 & 0.216 & 0.337 & 0.217 & 0.340 & 0.227 \\
\hline \multicolumn{2}{|c|}{ Number of rooms in the dwelling } & 2.872 & 2.727 & 2.828 & 2.827 & 2.833 & 2.776 & 2.828 \\
\hline \multirow[t]{3}{*}{ Area } & Rural & 0.373 & 0.410 & 0.377 & 0.452 & 0.381 & 0.421 & 0.384 \\
\hline & Mixed & 0.336 & 0.320 & 0.338 & 0.261 & 0.333 & 0.313 & 0.331 \\
\hline & Urban & 0.291 & 0.270 & 0.284 & 0.287 & 0.286 & 0.267 & 0.284 \\
\hline \multicolumn{2}{|c|}{ Receipt of remittances } & 0.075 & 0.104 & 0.075 & 0.169 & 0.000 & 1.000 & 0.083 \\
\hline \multicolumn{2}{|c|}{ Number of observations } & 7,068 & 3,061 & 9,188 & 941 & 9,285 & 844 & 10,129 \\
\hline
\end{tabular}

Source: authors' calculations, LSMS BIH 2002-2004. 
Table 2. Random and fixed effect estimates of emigration intention and receipt of remittances

\begin{tabular}{|c|c|c|c|c|c|c|c|c|c|c|c|c|c|c|c|}
\hline \multicolumn{2}{|l|}{ Variables } & \multicolumn{6}{|c|}{ Preferences for moving abroad } & \multicolumn{6}{|c|}{ Possible migration in the coming year } & \multicolumn{2}{|c|}{ Remittances } \\
\hline Constant & & $-0.598 * * *$ & $(-4.33)$ & -0.072 & $(-0.53)$ & & & $-2.302 * * *$ & $(-11.47)$ & $-0530 * *$ & $(-208)$ & & & & \\
\hline Female & & 0.055 & $(1.23)$ & -0.004 & $(-0.11)$ & & & $0.109 * *$ & $(1.98)$ & 0.024 & $(0.38)$ & & & $-0.194 * * *$ & $(-2.80)$ \\
\hline Age & $20-24$ & $0.140 * *$ & $(2.41)$ & 0.020 & $(0.33)$ & 0.121 & $(0.89)$ & 0.085 & $(1.18)$ & 0.055 & $(0.64)$ & 0.045 & $(0.24)$ & -0.030 & $(-0.32)$ \\
\hline \multirow[t]{4}{*}{ (ref: 15-19) } & $25-29$ & $0.107^{*}$ & $(1.72)$ & 0.074 & (1.13) & 0.053 & $(0.33)$ & $0.132 *$ & $(1.70)$ & 0.119 & $(1.25)$ & 0.270 & (1.21) & 0.023 & $(0.25)$ \\
\hline & $30-34$ & 0.038 & $(0.60)$ & 0.067 & (0.99) & 0.208 & (1.31) & 0.073 & $(0.88)$ & 0.084 & $(0.82)$ & 0.119 & $(0.47)$ & 0.045 & $(0.46)$ \\
\hline & $35-39$ & $-0.212^{* * *}$ & $(-3.16)$ & -0.040 & $(-0.55)$ & -0.194 & $(-1.10)$ & -0.073 & $(-0.80)$ & 0.166 & $(1.41)$ & 0.152 & $(0.50)$ & -0.130 & $(-1.28)$ \\
\hline & $40-45$ & $-0.406^{* * *}$ & $(-6.50)$ & -0.032 & $(-0.47)$ & -0.368 & $(-1.53)$ & $-0.281 * * *$ & $(-3.21)$ & 0.108 & $(0.88)$ & 0.122 & $(0.28)$ & 0.037 & $(0.41)$ \\
\hline \multirow{2}{*}{$\begin{array}{l}\text { Marital status } \\
\text { (ref: married) }\end{array}$} & Divorced/widowed & 0.006 & $(0.06)$ & 0.094 & $(0.90)$ & $0.745 * *$ & $(2.17)$ & 0.032 & $(0.22)$ & 0.018 & $(0.09)$ & 0.575 & $(1.00)$ & 0.205 & (1.47) \\
\hline & Single & $0.187^{* * *}$ & $(3.77)$ & $0.080 *$ & (1.67) & $0.489 * *$ & $(2.23)$ & $0.394 * * *$ & $(6.32)$ & $0.140^{*}$ & $(1.94)$ & $0.574^{*}$ & (1.79) & $-0.264 * * *$ & $(-3.43)$ \\
\hline \multicolumn{2}{|c|}{ Number of persons in the household } & -0.012 & $(-0.84)$ & 0.016 & $(1.12)$ & 0.102 & $(1.53)$ & $-0.057 * * *$ & $(-2.98)$ & -0.009 & $(-0.39)$ & -0.095 & $(-0.99)$ & $-0.103 * * *$ & $(-4.50)$ \\
\hline Education & Primary school & $0.303 * * *$ & $(2.98)$ & 0.031 & $(0.31)$ & & & $0.395 * * *$ & $(2.61)$ & 0.168 & $(0.82)$ & & & 0.140 & $(0.94)$ \\
\hline \multirow[t]{2}{*}{ (ref: no education) } & ) Secondary school & $0.297 * * *$ & $(2.90)$ & 0.062 & $(0.62)$ & & & $0.427^{* * *}$ & $(2.82)$ & 0.204 & $(0.99)$ & & & 0.055 & $(0.37)$ \\
\hline & Junior college/University & $0.289 * *$ & $(1.96)$ & 0.099 & (0.67) & & & $0.493^{* *}$ & $(2.48)$ & 0.165 & $(0.64)$ & & & -0.084 & $(-0.39)$ \\
\hline \multicolumn{2}{|c|}{ Excellent self-reported health } & 0.029 & $(0.74)$ & 0.051 & (1.16) & 0.003 & $(0.03)$ & $0.219 * * *$ & $(4.36)$ & 0.061 & $(0.96)$ & 0.023 & $(0.20)$ & -0.049 & $(-0.80)$ \\
\hline \multicolumn{2}{|c|}{ Has a job } & 0.003 & $(0.07)$ & -0.008 & $(-0.15)$ & -0.103 & $(-0.73)$ & -0.008 & $(-0.11)$ & 0.010 & $(0.12)$ & -0.126 & $(-0.61)$ & $-0.146 *$ & $(-1.84)$ \\
\hline \multicolumn{2}{|l|}{ Unemployed } & $0.218^{* * *}$ & $(4.41)$ & -0.022 & $(-0.43)$ & -0.022 & $(-0.19)$ & $0.221 * * *$ & $(3.48)$ & 0.042 & $(0.54)$ & 0.050 & $(0.28)$ & $0.193 * * *$ & (2.63) \\
\hline \multirow{4}{*}{$\begin{array}{l}\text { Financial situation } \\
\text { (ref: very difficult) }\end{array}$} & Quite difficult & -0.035 & $(-0.62)$ & $0.146^{* *}$ & $(2.34)$ & 0.089 & $(0.78)$ & $0.136^{*}$ & $(1.69)$ & 0.072 & $(0.68)$ & 0.112 & $(0.59)$ & & \\
\hline & Just about getting by & $-0.396 * * *$ & $(-7.21)$ & $-0.125^{* *}$ & $(-2.11)$ & $-0.363^{* * *}$ & $(-3.15)$ & 0.043 & $(0.56)$ & 0.047 & $(0.47)$ & -0.072 & $(-0.38)$ & & \\
\hline & Doing alright & $-0.830 * * *$ & $(-12.73)$ & $-0.389 * * *$ & $(-5.59)$ & $-0.937 * * *$ & $(-6.41)$ & -0.098 & $(-1.12)$ & 0.027 & $(0.24)$ & -0.097 & $(-0.42)$ & & \\
\hline & Living comfortably & $-1.098 * * *$ & $(-9.11)$ & $-0.618 * * *$ & $(-4.87)$ & $-1.798 * * *$ & $(-5.98)$ & -0.197 & $(-1.33)$ & -0.172 & $(-0.95)$ & $-0.854 * *$ & $(-2.08)$ & & \\
\hline \multicolumn{2}{|l|}{ Wealth index } & 0.011 & $(0.88)$ & $0.026^{* *}$ & $(2.14)$ & & & $0.028^{*}$ & $(1.88)$ & 0.006 & $(0.39)$ & & & & \\
\hline \multicolumn{2}{|c|}{ Number of rooms in the dwelling } & $-0.050 * * *$ & $(-3.16)$ & $-0.038 * *$ & $(-2.23)$ & $-0.134 * * *$ & $(-3.29)$ & -0.020 & $(-1.01)$ & $-0.049 *$ & $(-1.95)$ & $-0.130 * *$ & $(-2.29)$ & & \\
\hline Area & Rural & $0.200 * * *$ & $(3.70)$ & 0.036 & $(0.73)$ & & & $0.189 * * *$ & $(2.87)$ & 0.077 & $(1.08)$ & & & 0.116 & $(1.42)$ \\
\hline (ref: urban) & Mixed & -0.006 & $(-0.11)$ & -0.021 & $(-0.40)$ & & & $-0.117^{*}$ & $(-1.69)$ & -0.009 & $(-0.11)$ & & & -0.021 & $(-0.25)$ \\
\hline \multicolumn{2}{|c|}{ Receipt of remittances } & $0.223 * * *$ & $(3.61)$ & 0.083 & $(1.20)$ & 0.113 & $(0.83)$ & $0.574^{* * *}$ & (7.98) & $0.226^{* *}$ & $(2.57)$ & $0.522 * * *$ & (2.96) & & \\
\hline \multicolumn{2}{|c|}{ Random/fixed effect } & RANDOM & & FIXED & & FIXED & & RANDOM & & RANDOM & & FIXED & & RANDOM & \\
\hline \multicolumn{2}{|c|}{ Number of observations } & 10129 & & 4361 & & 4361 & & 10129 & & 1925 & & 1925 & & 10129 & \\
\hline \multicolumn{2}{|c|}{ Number of individuals } & 3604 & & 1490 & & 1490 & & 3604 & & 660 & & 660 & & 3604 & \\
\hline \multicolumn{2}{|l|}{ Log likelihood } & -5571.4 & & -2950.4 & & -1522.7 & & -2832.0 & & -1296.1 & & -688.6 & & -2649.2 & \\
\hline
\end{tabular}

Source: authors' calculations, LSMS BIH 2002-2004.

Note: (1A), (1B), (2A), (2B) and (3) are random effect Probit model, $(1 \mathrm{C})$ and $(2 \mathrm{C})$ are fixed effect Logit model. Significance levels are respectively $1 \%(* * *), 5 \%(* *)$ and $10 \%(*)$. 
Table 3. Matching estimators of remittances on emigration intention, based on selection of observables

\begin{tabular}{|c|c|c|c|c|}
\hline Variables & $\begin{array}{c}\text { Treated } \\
\text { (remittances) }\end{array}$ & $\begin{array}{c}\text { Control } \\
\text { (no remittances) }\end{array}$ & Difference & \\
\hline \multicolumn{5}{|l|}{ Panel A. Preferences for moving abroad } \\
\hline \multicolumn{5}{|c|}{ A1. Whole sample (3,604 ind. - 10,129 obs.) } \\
\hline Linear estimator (without matching) & 0.376 & 0.296 & $0.080 * * *$ & $(t=4.85)$ \\
\hline Propensity score matching & 0.376 & 0.299 & $0.077^{* * *}$ & $(\mathrm{t}=4.43)$ \\
\hline Coarsened exact matching & 0.386 & 0.306 & $0.080 * * *$ & $(t=4.06)$ \\
\hline Entropy balancing & 0.376 & 0.300 & $0.075^{* * *}$ & $(t=4.32)$ \\
\hline \multicolumn{5}{|c|}{ Possible migration to a foreign country in the coming year } \\
\hline \multicolumn{5}{|c|}{ A2. Sample with change in preferences ( 1,490 ind. $-4,361$ obs.) } \\
\hline Linear estimator (without matching) & 0.492 & 0.458 & 0.034 & $(\mathrm{t}=1.28)$ \\
\hline Propensity score matching & 0.492 & 0.458 & 0.034 & $(\mathrm{t}=1.25)$ \\
\hline Coarsened exact matching & 0.491 & 0.459 & 0.031 & $(t=0.90)$ \\
\hline Entropy balancing & 0.492 & 0.456 & 0.036 & $(\mathrm{t}=1.33)$ \\
\hline \multicolumn{5}{|c|}{ Panel B. Possible migration to a foreign country in the coming year } \\
\hline \multicolumn{5}{|c|}{ B1. Whole sample $(3,604$ ind. $-10,129$ obs. $)$} \\
\hline Linear estimator (without matching) & 0.188 & 0.084 & $0.104 * * *$ & $(t=10.03)$ \\
\hline Propensity score matching & 0.188 & 0.082 & $0.106^{* * *}$ & $(t=7.69)$ \\
\hline Coarsened exact matching & 0.185 & 0.074 & $0.111^{* * *}$ & $(t=9.03)$ \\
\hline Entropy balancing & 0.188 & 0.082 & $0.106 * * *$ & $(t=7.67)$ \\
\hline \multicolumn{5}{|c|}{ B2. Sample with change in preferences (1,925 ind. -660 obs.) } \\
\hline Linear estimator (without matching) & 0.492 & 0.407 & $0.084 * *$ & $(t=2.50)$ \\
\hline Propensity score matching & 0.492 & 0.404 & $0.088 * *$ & $(t=2.54)$ \\
\hline Coarsened exact matching & 0.496 & 0.353 & $0.143^{* * *}$ & $(t=2.77)$ \\
\hline Entropy balancing & 0.492 & 0.403 & $0.089 * *$ & $(t=2.56)$ \\
\hline
\end{tabular}

Source: authors' calculations, LSMS BIH 2002-2004.

Note: significance levels are respectively $1 \%(* * *), 5 \%(* *)$ and $10 \%(*)$. 
i For a related model where migration and consumption decisions are taken simultaneously, see for instance Dustmann (1997). Dustmann (2003) adds family considerations (parental concern about children) in the explanation of return migration.

ii This simple conceptual framework can be extended further, for instance by bringing arguments from the exchange theory on remittances and trying to get further incentives about the differences in characteristics of migrants and those left behind and the related links with the decision to remit among the former and to emigrate on the part of the latter. For instance, Stark (2005) describes a situation whereby migrants may be interested in sending home remittances as a "bribe" for their unskilled relatives to not out-migrate. By contrast, Stark and Wang (2002) argue that migrants may be better off paying their unskilled relatives to follow in their footstep in order to dilute the pool of migrant workers.

iii Using a poverty headcount ratio at \$2 a day, the percentage of the Bosnian population below that poverty line was $29 \%$ in 2001 and $34 \%$ in 2004.

iv These data are publicly available on the World Bank website. For a detailed description, see the following url: http://econ.worldbank.org/WBSITE/EXTERNAL/EXTDEC/EXTRESEARCH/EXTLSMS/0,,contentMDK:21485765 menuPK:41969 52 pagePK:64168445 piPK:64168309 theSitePK:3358997 isCURL:Y,00.html.

${ }^{\vee}$ The master sample was based on a selection of 146 municipalities, which were grouped into three strata (urban, rural and mixed). Urban municipalities are those where 65 percent or more of the households are considered to be urban, while rural municipalities are those where the proportion of urban households is below 35 percent.

${ }^{v i}$ This exclusion of the first wave does not entail any selection bias since we do not use any specific information from that wave (like lagged values of covariates) and account for all individuals in the household interviewed at each wave. All happens as if we consider a fresh sample starting in 2002.

vii We also constructed an ordered indicator ranging from 1 (migration in the coming year not likely at all) to 4 (migration very likely) to assess the robustness of our findings. The results are very similar to the ones we obtain with the use of the binary variable.

viii The wealth indicator is a linear index of asset ownership, constructed with the use of the principal-component analysis suggested by Filmer and Pritchett (2001).

${ }^{\text {ix }}$ We do not explicitly consider the possibility of a measurement error in the recording of remittances as there is little one could do about it and any study in this area would potentially be fraught with this problem.

${ }^{x}$ Also, the receipt of remittances potentially affects the behaviour of all family members living in the household.

${ }^{x i}$ This assumption of time-invariance is very similar to that necessary for the standard difference-in-differences estimator with matching.

xii The effect of primary education on the desire to migrate is stronger than the effect of higher than primary levels of education compared to the omitted category of no education, but the opposite is true when the outcome variable is the likelihood of an individual to migrate in the coming year.

xiii The only positive and significant financial situation variable in the likelihood to migrate regression is that of a quite difficult situation compared to the omitted category of a very difficult situation. However, even this variable is only significant at the $10 \%$ level.

${ }^{\text {xiv }}$ This covariate is potentially endogenous if the smaller size of households is a result of migration that has already taken place.

${ }^{x v}$ By definition, individuals whose dependent variable does not vary over time do not contribute to the conditional likelihood. 
${ }^{x v i}$ Estimates from a fixed effect linear regression on the whole sample $(3,604$ individuals) indicate that the probability to migrate in the coming year is reduced by 4.6 percentage points $(t=3.68)$.

xvii In the absence of detailed characteristics of the donors of remittances, it is difficult to pin our set of results to any specific theory of remittance behavior. As emphasized in the economic literature (Rapoport and Docquier, 2006), it remains typically difficult to discriminate between the various motives for remittances.

xviii The main advantage of the last two estimators is that they reweight directly units to achieve balance between both control and treated groups of observations. This avoids the complex two-stage procedure of the propensity score approach which consists in first estimating weights obtained from a Probit or Logit regression explaining the treatment variable, then assessing whether the mean of each covariate does not differ between treated and control units after the matching.

${ }^{x i x}$ For the calculation of standard errors, we turn to a procedure bootstrapping the sample at the respondent level.

${ }^{x x}$ We are indebted to an anonymous reviewer for this suggestion. These additional results are not reported, but available upon request from authors. The sample now comprises 5,066 individuals (14,909 observations). In our regressions, we include the same covariates as in Table 2 except for age which is introduced in a quadratic form.

${ }^{x \times i}$ For that purpose, we estimate a model explaining preferences for migration with a dummy for the 46-60 age group, a dummy for remittance receipt, and an interaction term crossing the 46-60 age group with transfer receipt (along with the other individual characteristics). Whatever the outcome under consideration, the crossed term is never significant at conventional level. 